\title{
Nonlinear dynamics of self-organising bubble departures from twin nozzles
}

\author{
P. Dzienis (i) $\cdot$ R. Mosdorf $\cdot$ T. Wyszkowski
}

Received: 3 January 2019/Accepted: 14 September 2019/Published online: 11 October 2019

(C) The Author(s) 2019

\begin{abstract}
The nonlinear dynamics of self-organising bubble departures from twin nozzles in engine oils was analysed. Air bubbles were generated from twin brass nozzles with an inner diameter equal to $1 \mathrm{~mm}$. The flow of bubbles in bubble chains was recorded using high-speed camera. The time series of air pressure oscillations and signal from laser-phototransistor identifying the presence of bubbles over the nozzles outlet were recorded simultaneously. The self-organising bubble departures were observed and their stability was analysed. It was found that self-organising bubble departures become unstable because of successive (during subsequent bubble departures) decrease of the mean air pressure in one of the nozzle air supply system. It was shown that instability of selforganising bubble departures leads to equalization of pressures in both nozzles air supply systems which causes that simultaneous bubble departures appear. In the present experiment, this process was repeated in a cyclic and chaotic way. It was shown that stable selforganising bubble departures are accompanied by periodic air pressure oscillations in one of the nozzles and chaotic air pressure oscillations in the second one.
\end{abstract}

Keywords Bubble $\cdot$ Bubble chain $\cdot$ Self-organising bubble departures $\cdot$ Nonlinear data analysis

P. Dzienis $(\bowtie) \cdot R$. Mosdorf · T. Wyszkowski Faculty of Mechanical Engineering, Bialystok University of Technology, Wiejska 45C, 15-351 Białystok, Poland e-mail: p.dzienis@pb.edu.pl

\section{Introduction}

The self-organising bubble departures were observed in many experimental investigations. Such experiments were carried out in systems with orifice [1] and nozzles [2, 3]. In the paper [1] bubble formation at two, three, four and six symmetrical orifices was investigated. In this experiment, the same gas supply system was used to all orifices. It was concluded that the spacing between orifices can affect the bubbles' synchronicity via liquid pressure effects due to bubble-to-bubble interaction, coalescence and the wake pressure of preceding bubbles. The mechanisms of self-organising bubble departures creation from independent nozzles can give comprehensive information about the physical process accompanying the self-organising mechanism. The carried out analysis $[2,3]$ shows that self-organising mechanism of bubble departures depend on hydrodynamic interactions between bubbles. Such interactions modify the hydrodynamic condition above the nozzle outlets and, finally, they modify the air pressure oscillations in air supply systems [4-6]. The air pressure oscillations, modified in such a way, influence the liquid flow above the nozzles outlet. The mechanism of interactions between nonstationary velocity liquid field over the nozzle outlets (generated by the flow of bubbles) and gas pressure oscillations in gas supply systems are not fully understood. Especially the phenomena 
responsible for the appearance of self-organising bubble departures are unknown.

The interactions between bubbles generated from two neighbouring micro-tubes were analysed and described in the paper [7]. During the experiment, bubbles were generated to the water and an aqueous glycerine solution. It was concluded that bubbles interactions and their coalescence depend on: liquid properties, gas flow rate and distance between tubes. In the papers [8-10] behaviours of the bubble moving in water and silicone oils were discussed. In the mentioned experiments, bubbles were generated from two adjacent orifices. It was shown that interactions between bubbles (coalescence or bubble bouncing) are depended on bubble Reynolds number. In the experiment pair of bubbles departed simultaneously. Alternative bubble departures (self-organising structure of bubble departures), in water from nozzles, were investigated in papers [2, 3]. In these experiments, the distance between nozzles was changed from $3 \mathrm{~mm}$ up to $10 \mathrm{~mm}$. It has been shown that the appearance of alternative bubble departures depends on the distance between nozzles, their arrangement and the air volume flow rate. During the alternative bubble departures, bubbles departed from neighbouring nozzles interact with each other. Bubbles departed from the one nozzle attract the bubble growing on the adjacent nozzle and it causes the formation of the unique structure of the bubble chain. During alternative bubble departures, bubbles depart periodically form self-organising bubble flow.

The dynamics of bubble departures from the single glass nozzle [11] and single orifice [12] were also analysed. It was shown that bubbles dynamics has deterministic chaos character and depending on the volume flow rate and nozzle or orifice diameter. It has been shown that periodic bubble departure, from the single nozzle, can be stabilized by the increase of air volume flow rate.

In the present paper, the phenomena responsible for self-organising bubble departures from twin nozzles in engine oils are analysed. The flow of gas bubbles in oils occurs in hydrocarbons industries and chemical processes, for example in oil pipelines or petrochemical industry. The dynamics of bubble formation is used during oils degassing (by initiating their movement in a liquid, e.g. using vacuum pumps) — the gas is removing from liquid by moving bubble. Moreover, the flow of the gas bubble is a fundamental aspect relevant in environmental applications - studies of the release of underwater methane, which contribute to the global greenhouse effect $[13,14]$. Understanding the interaction between gas bubbles moving in oils would be useful in optimizing the devices for degassing or transporting oils [15]. The present experiment was carried out with using twin nozzles with independent air supply system in our opinion such experimental stand contraction allows as to observe only the hydrodynamic interactions between departing bubbles. In experiments with orifices additionally, the interactions between bubbles in common air supply system occur.

The flow of bubbles in oils is slower in comparison with the flow of bubbles in the water. It causes that mutual interactions between the flow of bubbles and pressure oscillations in gas supply systems are easier to investigate. During the experiment, the air volume flow rate and the distance between the nozzles were changed. Time series of: pressure oscillations in independent gas supply systems, laser - phototransistor signal and videos were recorded simultaneously. Time series of correlation coefficients, calculated in the moving window, were analysed using non-linear analysis methods. Such analysis allows identifying the character of bubble departures.

The structure of the paper is as follows. In Sect. 2 the experimental setup and data characteristics are described. The results of the experiment and nonlinear analysis are shown in Sect. 3. In Sect. 4 the pressure oscillations during the bubble departures are described. In Sect. 5 the bubble departure synchronization is discussed.

\section{Experimental setup and data characteristics}

In the experiment, bubbles were generated from two brass nozzles, placed at the bottom of a tank $(400 \times 400 \times 700 \mathrm{~mm})$, to: mineral and synthetic engine oils. Kinematic viscosity of mineral oil was equal to $107 \mathrm{~mm}^{2} / \mathrm{s}$ and its density was equal to $850 \mathrm{~kg} / \mathrm{m}^{3}$ (for liquid temperature $20{ }^{\circ} \mathrm{C}$ ). Kinematic viscosity of synthetic oil was equal to $53 \mathrm{~mm}^{2} / \mathrm{s}$ and its density was equal to $850 \mathrm{~kg} / \mathrm{m}^{3}$. Inner diameters of nozzles were equal to $1 \mathrm{~mm}$. The schema of the experimental setup is shown in Fig. 1.

During the experiment investigations distance between nozzles $(S)$ was set on: $4 \mathrm{~mm}, 8 \mathrm{~mm}$ and 


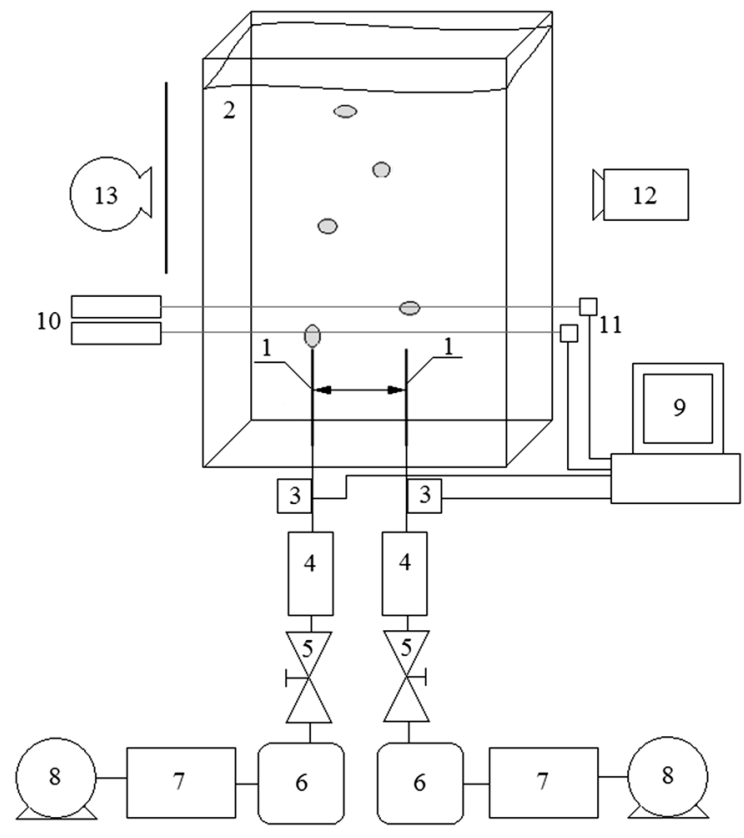

Fig. 1 Schema of experimental setup. 1-nozzles, 2-glass tank, 3-pressure sensors, 4-flowmeters, 5-air valves, 6-air tank, 7-pressure regulator, 8-air pomp, 9-computer acquisition system, 10-lasers, 11-phototransistors, 12-lasers, 13 -light source

$10 \mathrm{~mm}$. The air volume flow rate was changed in the range of $0.014 \mathrm{l} / \mathrm{min}$ to $0.125 \mathrm{l} / \mathrm{min}$. The air volume flow rate was measured using the flow meter (MEDSON s.c Sho-Rate-Europe Rev D, P10412A). The accuracy of the flow meter was equal to $5 \%$. The air pressure fluctuations in gas supply systems were measured using the silicon pressure sensor MPX12DP. A resolution of pressure sensors was equal to $5.5 \mathrm{mV} /$ $\mathrm{kPa}$ and its response speed was equal to $1 \mathrm{~ms}$. The stages of bubble growing and bubble waiting time were measured using the laser-phototransistor system. In the laser-phototransistor system the semiconductor red laser with wave length of $650 \mathrm{~nm}, 3 \mathrm{~mW}$, special aperture and phototransistor BPYP22 were used. During the experiment, the laser beam was placed $\sim 1 \mathrm{~mm}$ above the nozzle outlets. During the bubble growing time, the bubble was passing through the laser beam, at this time a voltage on the phototransistor was equal to $\sim 0.2 \mathrm{~V}$. After the bubble departed, the laser beam was not obscure and the value of voltage was equal to $\sim 4.8 \mathrm{~V}$. Signals from phototransistor were recorded simultaneously with time series of pressure changes using data acquisition system DT9800. The frequency of the sampling rate was equal to $1 \mathrm{kHz}$.

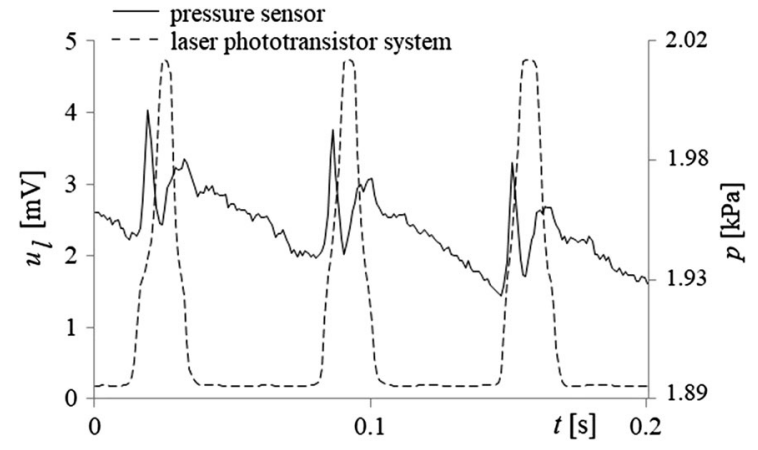

Fig. 2 Time series of laser-phototransistor and air pressure fluctuations (recorded in right nozzle for $q=0.0333 \mathrm{l} / \mathrm{min}$ and $S=4 \mathrm{~mm}$ )

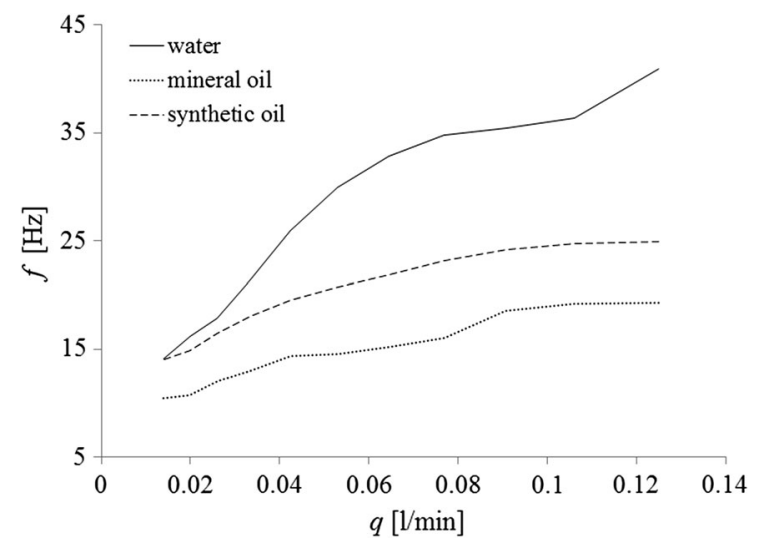

Fig. 3 Changes of bubble frequency versus air volume flow rate, for bubble departed in water and mineral and synthetic oils (estimated for bubbles departed from right nozzle for $S=10 \mathrm{~mm}$ )

Signals from laser-phototransistor and air pressure fluctuations are presented in Fig. 2. In Fig. 2 the pressure changes signals from phototransistor recorded in the right nozzle were presented ( $\mathrm{q}=0.0333 \mathrm{l} / \mathrm{min}$ and $S=4 \mathrm{~mm}$ ).

Changes of bubble departures frequency versus air volume flow rate, for bubble departed in water and engine oils are shown in Fig. 3. Bubble departures frequencies were estimated based on the FFT analysis of laser-phototransistors signals.

In Fig. 3 bubble departure frequencies were presented only for bubbles generated from the right nozzle (distance between nozzles equal to $10 \mathrm{~mm}$ ). The frequency of bubble departures is greater for bubble departed in water than the frequency of bubble departures in engine oils. Because the frequency of bubble departures in oils is lower than in water, 
(a)

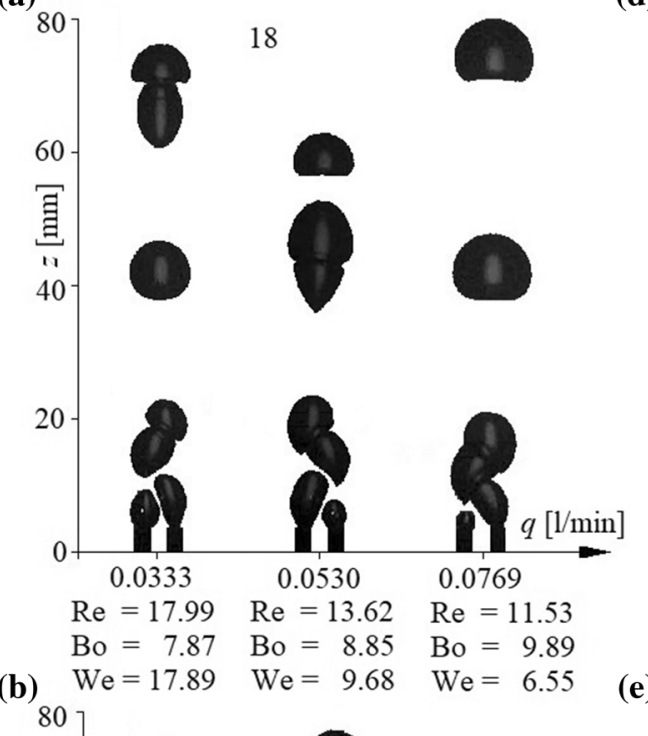

(d)

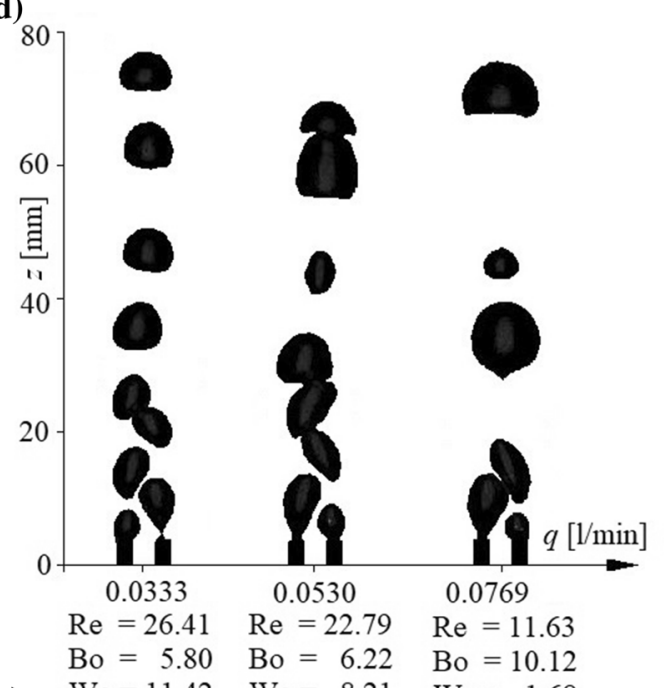

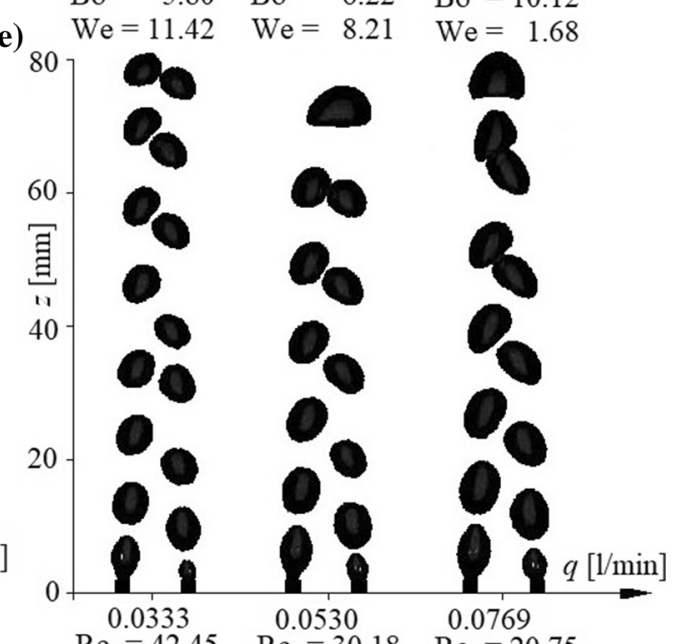

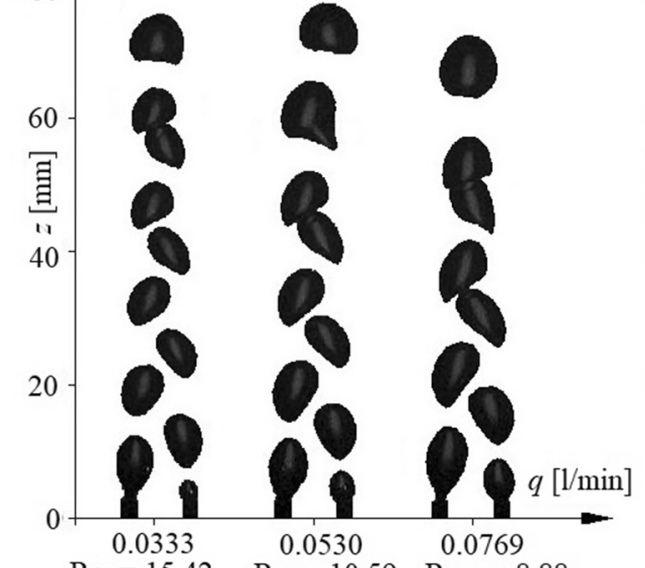

$\mathrm{Re}=15.42 \quad \mathrm{Re}=10.59 \quad \mathrm{Re}=8.88$

$\mathrm{Bo}=7.87 \quad \mathrm{Bo}=8.36 \quad \mathrm{Bo}=10.44$

(c) $\mathrm{We}=13.15 \quad \mathrm{We}=6.02 \quad \mathrm{We}=3.79 \quad$ (f)

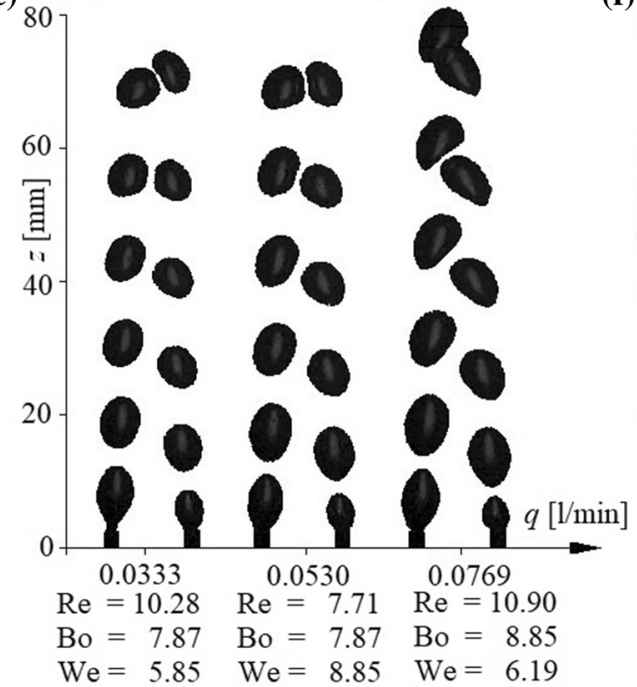

$\mathrm{We}=27.52 \quad \mathrm{We}=13.05 \quad \mathrm{We}=8.98$
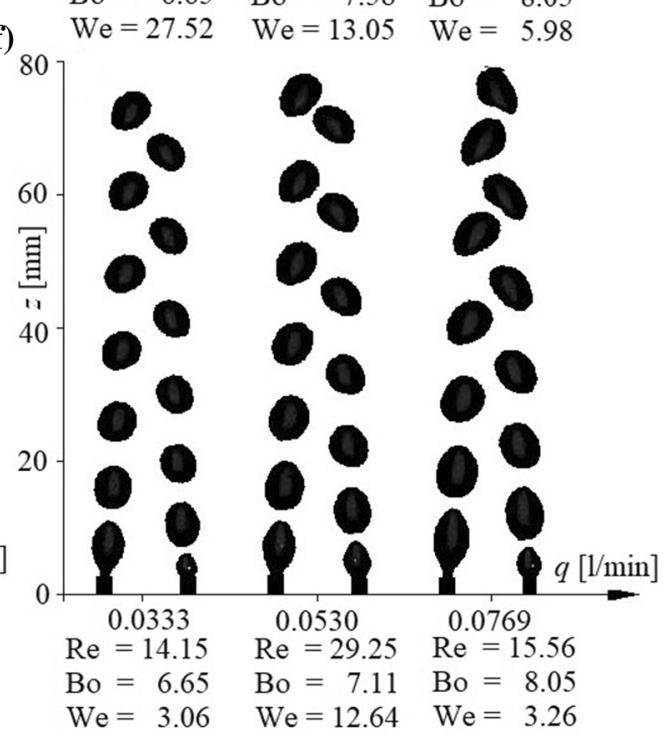
4Fig. 4 Flow structures of bubbles departed in engine oils for selected air volume flow rates $(q=0.0333 \mathrm{l} / \mathrm{min}, q=0.0530 \mathrm{l} /$ $\min , q=0.0769 \mathrm{l} / \mathrm{min}$ ) and distance between the nozzles. a distance between the nozzles $S=4 \mathrm{~mm}$-mineral oil, b distance between the nozzles $S=8 \mathrm{~mm}$-mineral oil, c distance between the nozzles $S=10 \mathrm{~mm}$-mineral oil, d distance between the nozzles $S=4 \mathrm{~mm}$ - synthetic oil, e distance between the nozzles $S=8 \mathrm{~mm}$-synthetic oil, f distance between the nozzles $S=10 \mathrm{~mm}$-synthetic oil

therefore the mutual interaction between the flow of bubbles and pressure oscillations in gas supply systems are easier to investigate. The formation of bubble chains was recorded using a high-speed camera-CASIO EX FX 1. Videos were recorded in grey scale with a speed of $600 \mathrm{fps}$.

In Fig. 4 flow structures of bubbles departed in engine oils for selected air volume flow rates $(q)$ and distances between the nozzles $(S) 4 \mathrm{~mm}, 8 \mathrm{~mm}$ and $10 \mathrm{~mm}$ are shown.

Bubbles which depart from twin nozzles in oils strive to move in the common chain. When the distance between nozzles is low, then bubbles coalesce (for example Fig. 4a, b). Changes of air volume flow rate and distance between nozzles modify the distance above the nozzle outlet, where the bubbles coalesce. In Fig. 4 the values of dimensionless numbers are presented. Values of Re, Bo, and We were estimated for bubble just after its departure, according to the following formulas:

$\operatorname{Re}=\frac{d_{b} v_{b}}{v_{L}}$

Bo $=\frac{g \Delta \rho d_{b}^{2}}{\sigma}$

$\mathrm{We}=\frac{\rho v^{2} d_{b}}{\sigma}$

where $d_{b}$-bubble diameter (just after its departure), $v_{b}$-bubble velocity (just after its departure), $v_{l}$ - the kinematic viscosity of the liquid, $g$ - the acceleration of gravity, $\Delta \rho$ - the difference in density of the phases $\sigma$ - the surface tension coefficient.

For estimation of bubble velocity the Sobel filter [16] based on convolution of an image with a small integer valued filter has been used to identify bubbles on the frames. Then, the bubbles have been filled with black pixels. The bubbles velocity was estimated according to bubble mass centre of the black images of the bubble movement. The error of bubbles mass centre was equal to $0.083 \mathrm{~mm}$.

\section{Pressure oscillations during the bubble departures}

In Fig. 5 there are presented: time series of pressure oscillations in air supply systems, 3D attractor reconstructions, and values of: bubble departures frequency, correlation dimension, time delay and largest Lyapunov exponent-for distance between nozzles equal to $4 \mathrm{~mm}$ and air volume flow rates $q=0.0530 \mathrm{l} / \mathrm{min}$, $q=0.0769 \mathrm{l} / \mathrm{min}$. Data are shown separately for right and left nozzles.

There are many methods of determination of proper value of time delay. In general, the large group of methods is based on the analysis of the correlation between the time series from which the coordinates of the attractor are created. The series created from the measurements, $x_{i}$, and the series created by successive values of the second coordinate, $x_{i+\tau}$ are used as a successive coordinates. When the value of $\tau$ is too small, the coordinates of subsequent points are linearly correlated, but when the $\tau$ is too large, the coordinates of subsequent points are not correlated. Therefore, choosing the proper value of $\tau$ is important for further analysis of attractor structure. Consequently, the time delay $(\tau)$ was calculated using the following criterion, proposed by Schuster [17]:

$C_{a}(\tau) \sim 0.5 C_{a}(0)$

where autocorrelation function $\left(C_{a}\right)$ had a form [17]:

$C_{a}(\tau)=\frac{1}{N} \sum_{i=0}^{n} x_{i} x_{i+\tau}$

where $N$-number of samples, $x_{i}$-value of $i$ sample.

The correlation dimension was calculated using Grassberger-Procaccia algorithm [18]. To identify the chaotic character of pressure oscillations the largest Lyapunov exponent was calculated according to the following formula [19]:

$L=\frac{1}{t} \sum_{j=1}^{m} \log _{2} \frac{d\left(x_{j+1}\right)}{d\left(x_{j}\right)}$

where $m$-number of examined points, $t$ - time of evolution, $d\left(x_{j}\right)$-distance between points at $t=0$, $d\left(x_{j}\right)$-distance between points at $t=t_{e}$. 
Fig. 5 The time series of pressure changes in gas supply system, 3D attractor reconstructions, and values of: bubble departure frequency, autocorrelation, time delay, Lyapunov exponent for distance between nozzle equal to $4 \mathrm{~mm}$. a left nozzle$q=0.0530 \mathrm{l} / \mathrm{min}, \mathbf{b}$ right nozzle $-q=0.0530 \mathrm{l} / \mathrm{min}$, c left nozzle $-q=0.0769 \mathrm{l} /$ min, $\mathbf{d}$ right nozzle$q=0.0769 \mathrm{l} / \mathrm{min}$
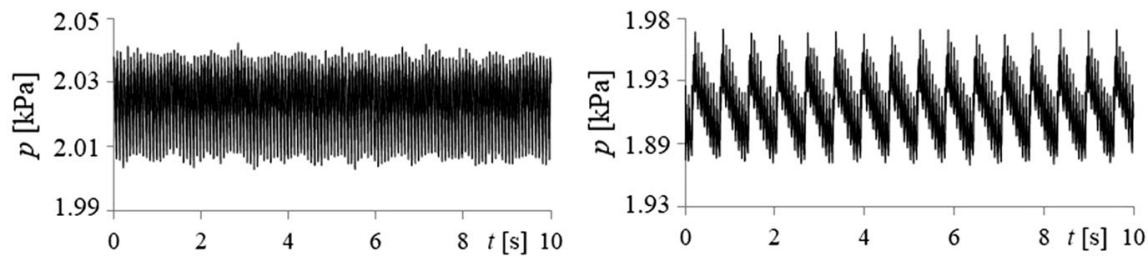

(a)

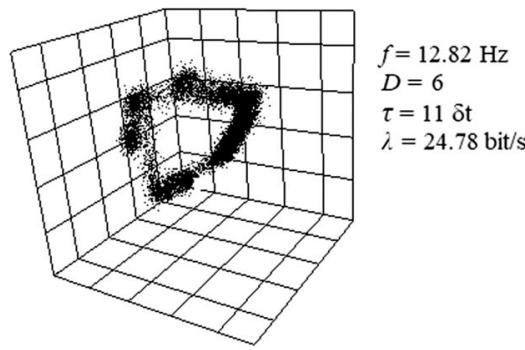

(b)
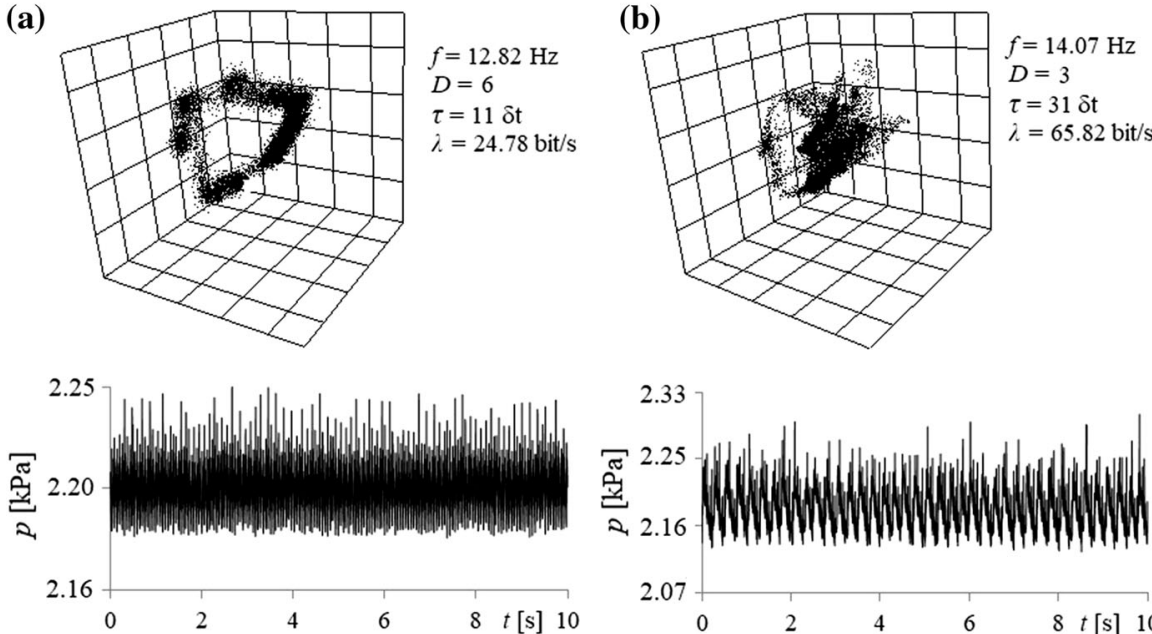

(c)

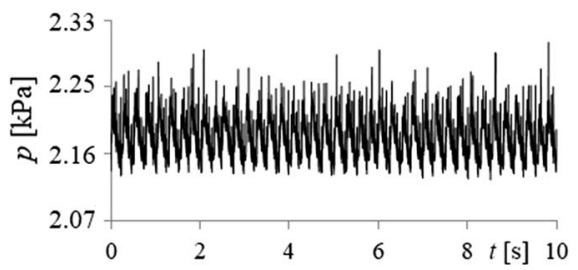

(d)

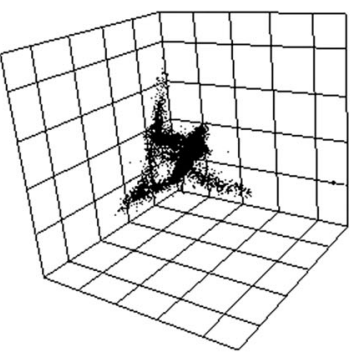

$f=17.65 \mathrm{~Hz}$

$D=5$

$\tau=4 \mathrm{dt}$

$\lambda=70.88 \mathrm{bit} / \mathrm{s}$

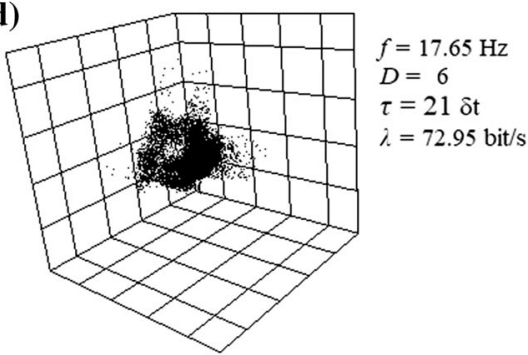

For estimation of the largest Lyapunov exponent, two points on the attractor immersed in $m$ dimensional space were selected. The distance between these points was equal to $d\left(x_{x j}\right)$. After the passage of certain time, the distance between selected points was calculated again and denoted as $d\left(_{x j+1}\right)$. When the value of $L$ is close to zero, then the pressure oscillations are periodic. When the value of the largest Lyapunov exponent is positive, then the system is capable of chaotic changes. When the value of the largest Lyapunov exponent increases, then the chaotic behaviours of the system become stronger.

In Fig. 6 time series of pressure changes in left and right nozzles are shown.

Pressure oscillations in the left nozzle are marked by dashed lines and continue lines for the right nozzle. Two marks (circle-left nozzle and ring-right nozzle) were used to show the moments of bubble departures.
Time periods, in which bubbles departed in alternative way, were marked by letter A and period, in which bubbles departed simultaneously, was marked by letter S.

It was observed that during the experiment, the average air pressure in one of the nozzles was slightly higher than the average air pressure in the second nozzle. This mean pressure difference decreases with an increase in the air volume flow rate, as shown in Fig. $6 a$ and b. In Fig. $6 a$ and $b$ the mean air pressure in the left nozzle was higher than in the right nozzle. In the nozzle, in which the average air pressure was lower (right nozzle-Fig. 6), the long-term pressure oscillations appear (what is clearly visible in Fig. 6a). In our experiment when the distance between nozzles was equal to $10 \mathrm{~mm}$ the difference between mean bubble departure frequencies was equal to $2.3 \mathrm{~Hz}$. The bubble departure frequency in the left nozzle was higher. 

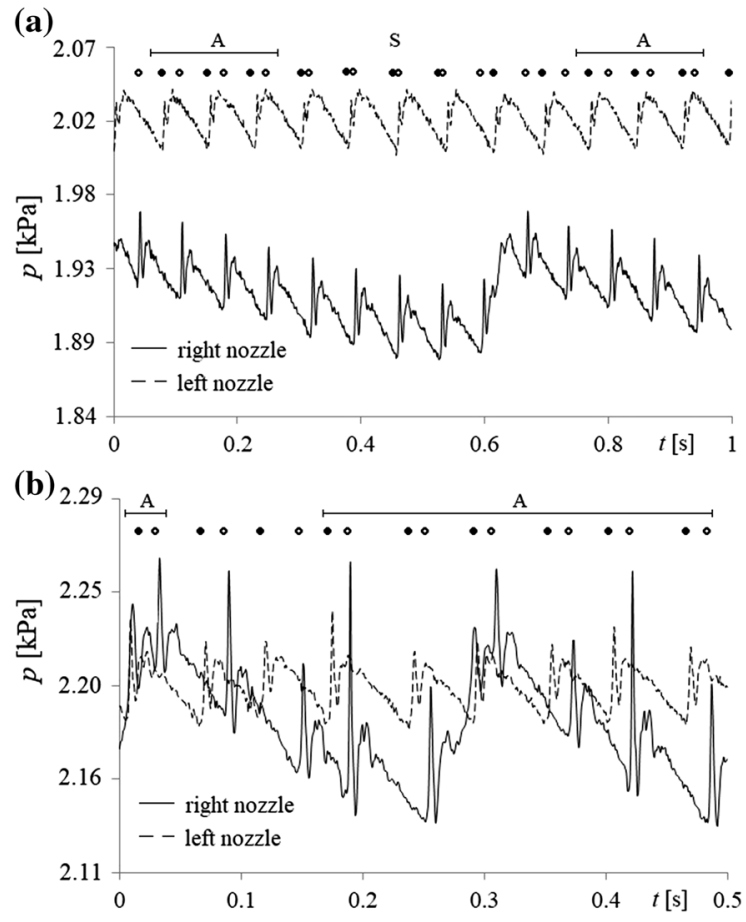

Fig. 6 Time series of pressure changes in gas supply system of left and right nozzles. a $q=0.0530 \mathrm{l} / \mathrm{min}$ and $S=4 \mathrm{~mm}$, b $q=0.0769 \mathrm{l} / \mathrm{min}$ and $S=4 \mathrm{~mm}$ (alternative bubble departures). The moment of bubble departures from left nozzle were marked by circles and the moment of bubble departures from right nozzle were marked by rings

The hydrodynamic interactions between bubbles cause that the difference between frequencies decreased. For air volume flow rate equal to $q=$ $0.0530 \mathrm{l} / \mathrm{min}$ and distance between nozzles equal to 4 (long term oscillations were observed) $\Delta f=1.2 \mathrm{~Hz}$. For the same air volume flow rate and distances between nozzles 6,8 and $10 \mathrm{~mm}$ the differences between frequencies were respectively to equal $1.9 \mathrm{~Hz}, 2.1 \mathrm{~Hz}$ and $2.3 \mathrm{~Hz}$. In those cases the long term oscillations did not occur. In our experiment the long term oscillations occur only in right nozzle therefore the left nozzle (where the long term oscillations do not appear) we called the master. The frequency of these oscillations changes with increase of air volume flow rate. The bubbles departed in almost periodic way from nozzle, in which the mean air pressure was greater, from another nozzle they departed non-periodically.

Experimental stand was prepared very carefully to ensure that air supply systems of left and right nozzles were identical. Pressure in the systems was tested at a constant pressure, and in this case the identical values of pressure were recorded in both systems. The increase in air flow rate also leads to the equalization of average air pressure in both nozzle air supply systems. The differences between average pressure in the left and right nozzles can be caused by small differences between the nozzle supply systems. Such small differences between nozzles and their supply systems seem to be a natural phenomenon - always present in experimental research.

The analysis of video frames and pressure fluctuations can be concluded as follows. Pressure fluctuations in the left nozzle take place between constant pressure values. However, the interactions between successively departing bubbles lead to a systematic decrease of pressure in the right nozzle gas supply system. This resulted in disappearance of alternative bubble departures and an increase in the pressure in the right nozzle gas supply system - the alternative bubble departures start again.

Furthermore, changes of pressure in one of the nozzles are periodic. In the second nozzle those changes are chaotic. One can suppose that, in order to preserve the alternative bubble departures, the pressure in one of the nozzles should change chaotically.

\section{Bubble departure synchronization}

The appearance of long term pressure oscillations unable using that correlation coefficient for analysis of synchronized bubble departures based on the pressure oscillations. Long term pressure oscillations cause that the correlation coefficient of pressure oscillations is close to 0 .

In order to analyse the appearance of synchronised bubble departures the signal from laser-phototransistor sensors were used $\left(x_{i, L}\right.$ - left nozzle, $x_{i, R}$-right nozzle). The correlation coefficient $C_{0.3 \mathrm{~s}}$ in the moving window of time period equal to $0.3 \mathrm{~s}$ was calculated. The correlation coefficient was calculated according to the following formula:

$C_{0.3 s}=\frac{\operatorname{Cov}\left(x_{i, L}, x_{i, R}\right)}{\sigma_{x, L}, \sigma_{x, R}}$

where cov-covariance, $\sigma$-standard deviation of signal. 

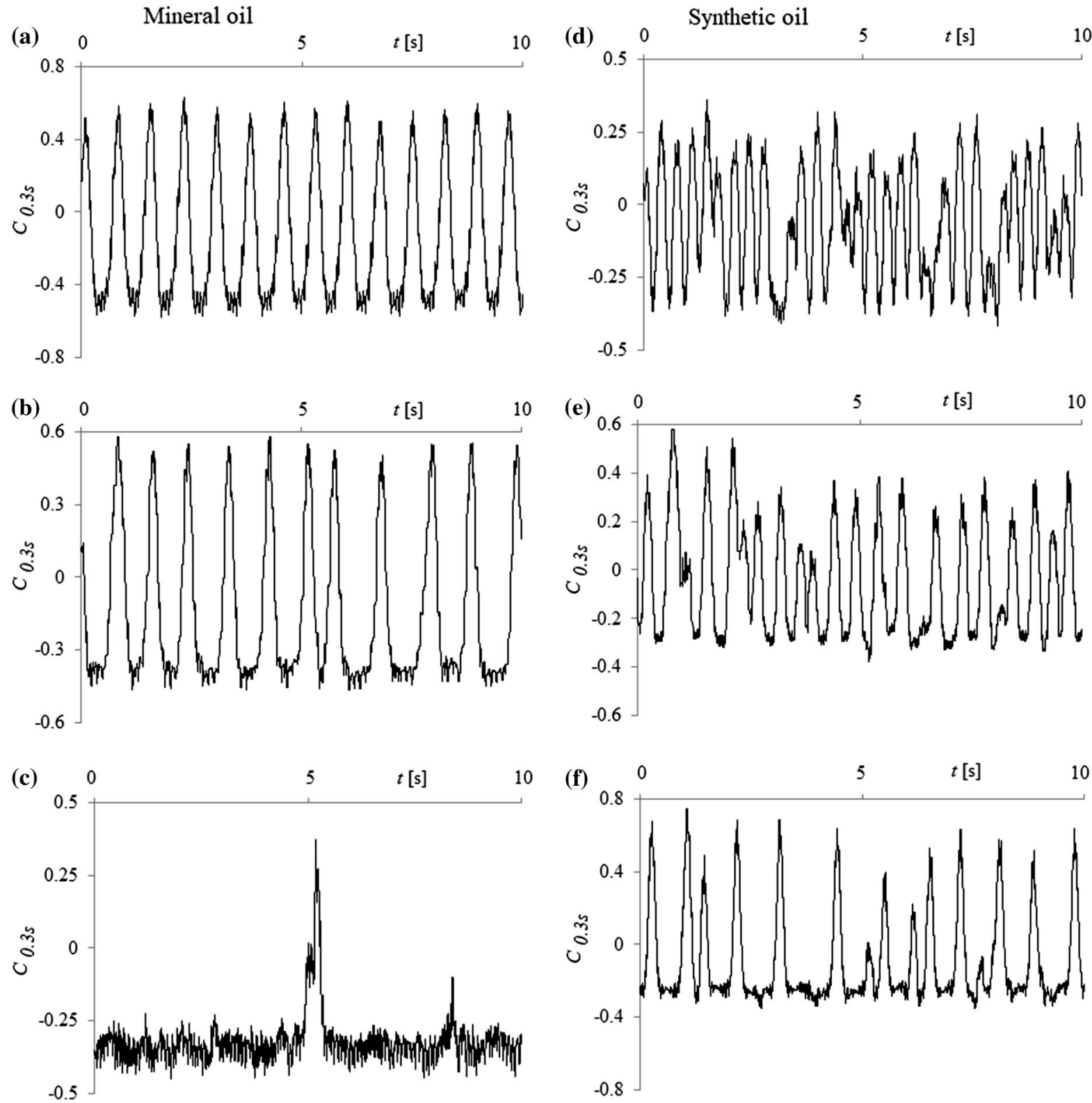

Fig. 7 Changes of correlation coefficient $C_{0.3 s}$ in mineral oil, for selected air volume flow rates, distance between nozzles $S=4 \mathrm{~mm}$. a $q=0.0333 \mathrm{l} / \mathrm{min}$-mineral engine oil, b $q=0.0530 \mathrm{l} / \mathrm{min}$-mineral engine oil, c $q=0.0769 \mathrm{l} /$

When $\left|C_{0.3 s}\right|$ is close to 1 , time series $x_{i, L}, x_{i, R}$ are correlated, but when $\left|C_{0.3 s}\right|$ is close to zero, the time series $x_{i, L}, x_{i, R}$ are not correlated. When value of $C_{0.3 s}$ is higher than 0 , then bubbles depart (from twin nozzle) in the same time. When value of $C_{0.3 s}$ is lower than 0 , then bubbles depart alternatively.

min-mineral engine oil, d $q=0.03331 / \mathrm{min}$ —synthetic engine oil, e $q=0.0530 \mathrm{l} / \mathrm{min}$-synthetic engine oils, f $q=0.0769 \mathrm{l} / \mathrm{min}$ - synthetic engine oils

The changes of correlation coefficient $C_{0.3 s}$ for selected air volume flow rates and mineral and synthetic engine oils are presented in Fig. 7, where the time series of $10 \mathrm{~s}$ are presented.

The value of correlation coefficient $C_{0.3 s}$ is negative for a relatively long period of time in case shown in Fig. 7c. In this case the alternative bubble departures 

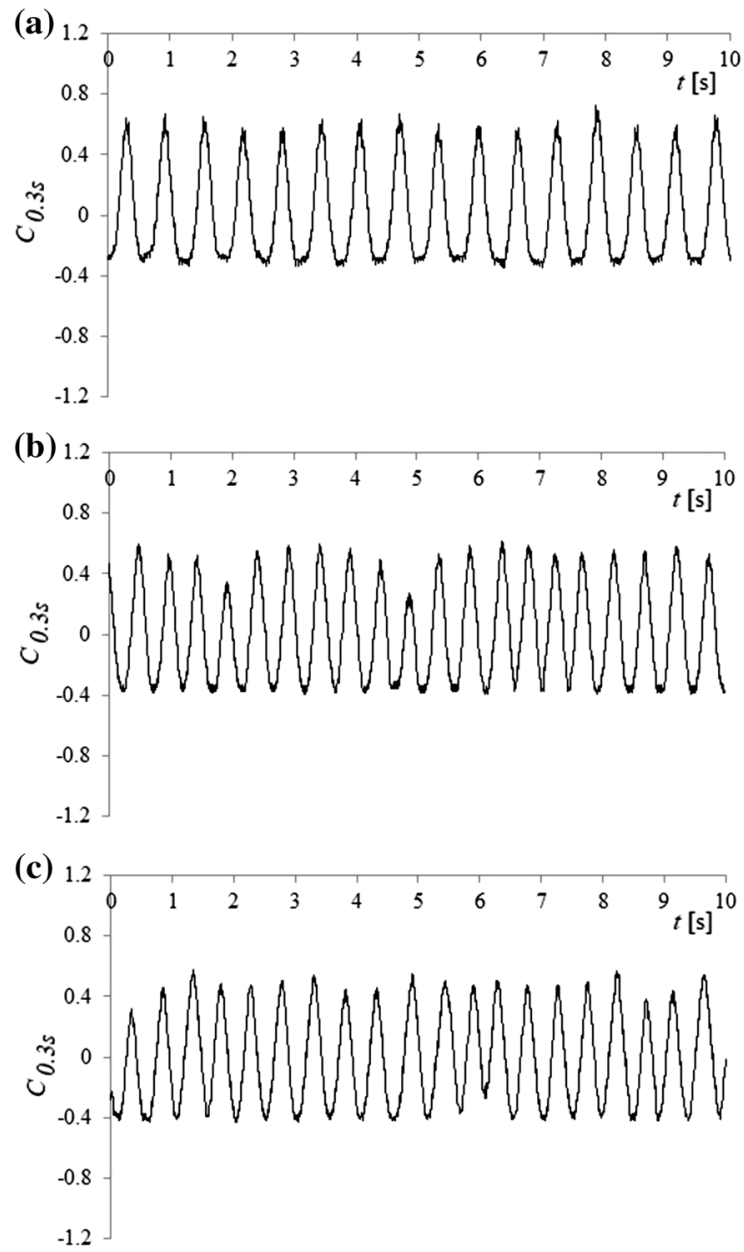

Fig. 8 Changes of correlation coefficient $C_{0.3 s}$ for air volume flow rates $q=0.0530 \mathrm{l} / \mathrm{min}$, synthetic oil and selected distances between nozzles. a $S=10 \mathrm{~mm}, \mathbf{b} S=8 \mathrm{~mm}$, c $S=6 \mathrm{~mm}$

are stable in a relatively long period of time. For other air volume flow rates the values of correlation coefficient $C_{0.3 s}$ oscillate between positive and negative values. It means that periods of alternative and simultaneous bubble departures occur one by one (Fig. 7a, b).

In synthetic oil the periods of appearance and disappearance of alternative bubble departures occur chaotically (Fig. 7d-f). The longest period of appearance of alternative bubble departures occurs in case shown in Fig. 7f.

In Fig. 8 the changes of correlation coefficient for air volume flow rate equal to $\mathrm{q}=0.0530 \mathrm{l} / \mathrm{min}$ and distances between nozzles $6 \mathrm{~mm}, 8 \mathrm{~mm}$ and $10 \mathrm{~mm}$ were shown.
At the distance between nozzles equal to $10 \mathrm{~mm}$, the bubble departures are almost periodic. The correlation coefficient oscillates with practically constant amplitude. Reducing the distance between the nozzles leads to appearance of irregular changes in the amplitude of the $C_{0.3 s}$ function. These changes are caused by the hydrodynamic interaction between the departing bubbles. The decrease of distance between nozzles leads to an increase in the hydrodynamic interaction between bubbles, therefore in the paper the bubble behaviours were analysed for $S=4 \mathrm{~mm}$. The same situation was observed for mineral oil.

Time series of correlation coefficient, $C_{0.3 s}$, were used for investigation of the periodicity of alternative bubble departures occurrence. 3D attractors reconstruction for air volume flow rates: $q=0.0333 \mathrm{l} / \mathrm{min}$, $q=0.0530 \mathrm{l} / \mathrm{min}, \quad q=0.0769 \mathrm{l} / \mathrm{min}, \quad$ distance between nozzles $S=4 \mathrm{~mm}$ and mineral and synthetic oils are presented in Fig. 9.

For air volume flow rates equal to $q=0.0333 \mathrm{l} /$ min (Fig. 9a) and $q=0.0530 \mathrm{l} / \mathrm{min}$ (Fig. 9b) the reconstructed trajectories of $3 \mathrm{D}$ attractors form a torus. It means that the transitions between alternative and simultaneous bubble departures are quasi periodic. When air volume flow rate is equal to $0.0769 \mathrm{l} /$ min, then the reconstructed trajectories are focused near the centre of the chart. In this case the alternative bubble departures occur in a long period of time.

In Fig. 9 the dominant frequency $(f)$, correlation dimension $(D)$, time delay $(\tau)$ and Lyapunov exponent ( $\lambda$ ) for time series of correlation coefficient changes are shown, $\delta_{t}$ is a sampling time period. The dominant frequency describes the changes of periods of simultaneous and alternative bubble departures. For the case presented in the Fig. $7 \mathrm{c}$ the dominant frequency estimates the frequency of $C_{0.3 s}$ fluctuations during the alternative bubble departures. The Lyapunov exponent was estimated using the Wolf method [18].

For mineral oil, when the air volume flow rate is equal to $0.0333 \mathrm{l} / \mathrm{min}$, the cycling transitions between the alternative and simultaneous bubble departures appear. In this case the Lyapunov exponent is equal to 7.47 [bit/s]. The increase of the air volume flow rate results in a loss of the periodicity of transition between the alternative and simultaneous bubble departures. At $q=0.0530 \mathrm{l} / \mathrm{min}$ the Lyapunov exponent is equal to 36.75 (bit/s). This means that the process has a deterministic chaos character. The Lyapunov exponent slightly decreases $[24$ (bits/s)], when 
Fig. 9 3D attractors from time series of changes of correlation coefficient $C_{0.3 \mathrm{~s}}$ in engine oils for selected air volume flow rates, distance between nozzles and $S=4 \mathrm{~mm}$ and mineral oil. a $q=0.0333 \mathrm{l} / \mathrm{min}-$ mineral oil, $\mathbf{b} q=0.0530 \mathrm{l} /$ min-mineral oil, c $q=0.07691 / \mathrm{min}-$ mineral oil, $\mathbf{d} q=0.0333 \mathrm{l} /$ min-synthetic oil, e $q=0.0530 \mathrm{l} / \mathrm{min}-$ synthetic oil, f $q=0.0769 \mathrm{l} / \mathrm{min}-$ synthetic oil

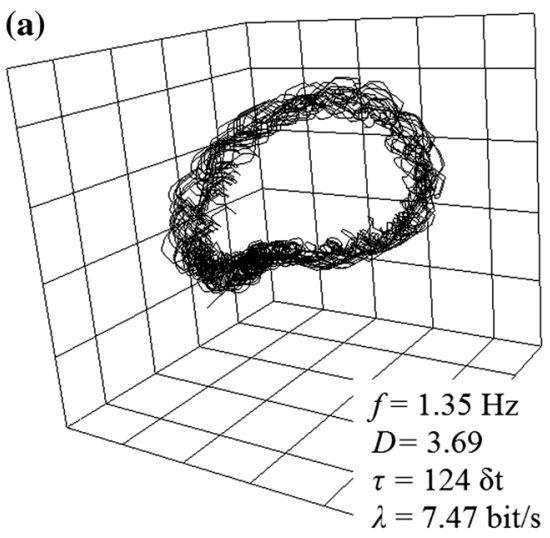

(d)
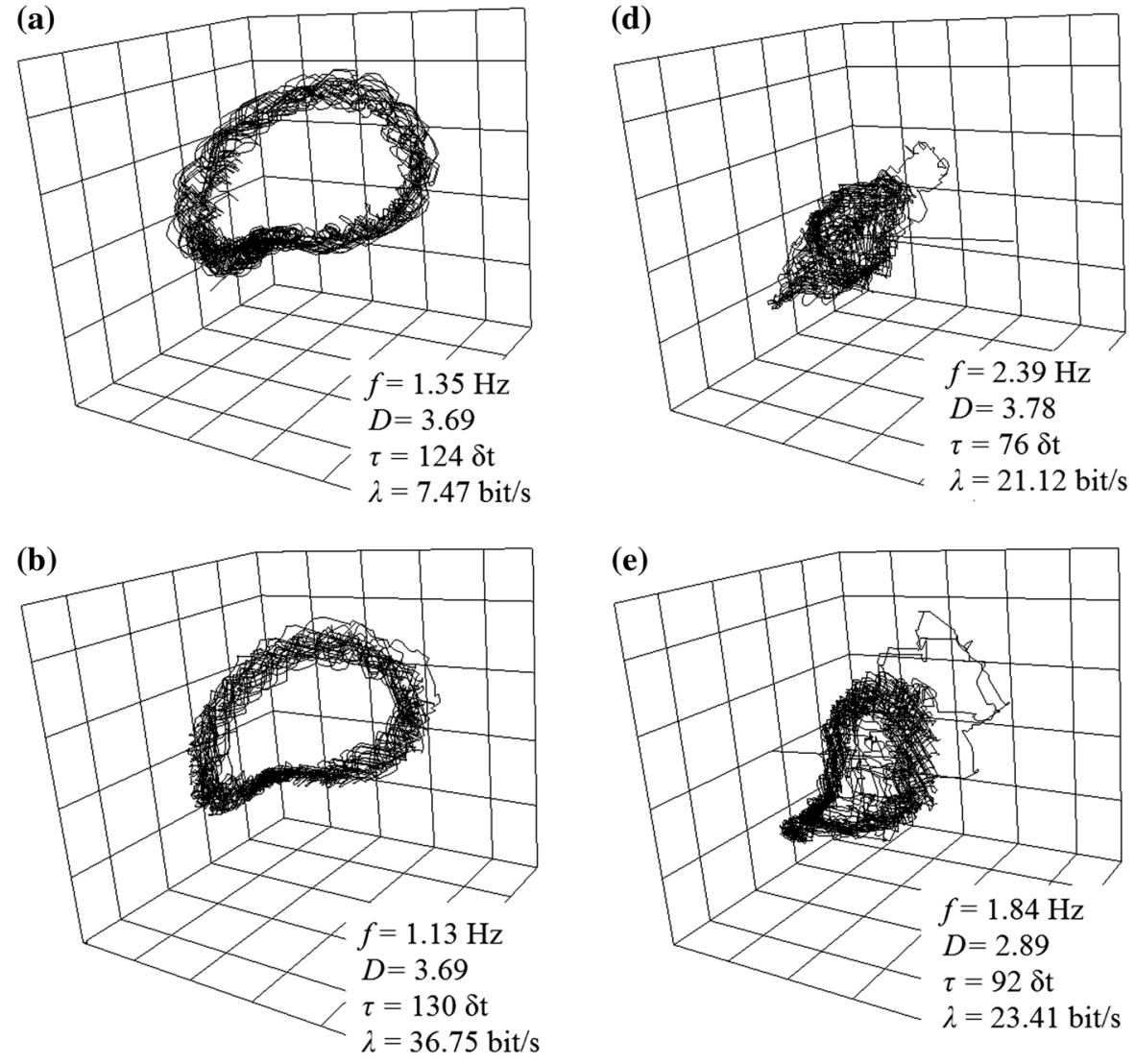

(e)

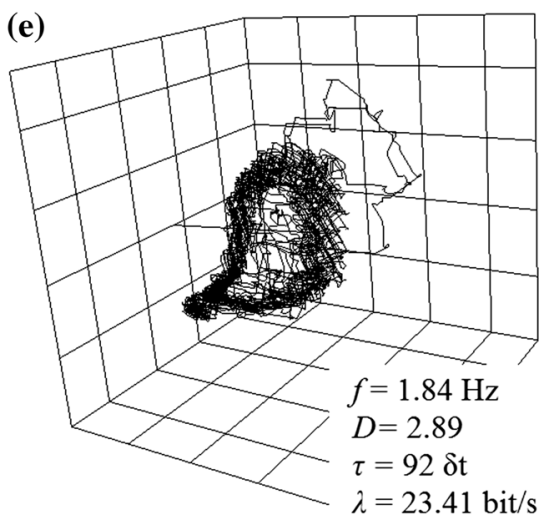

(f)

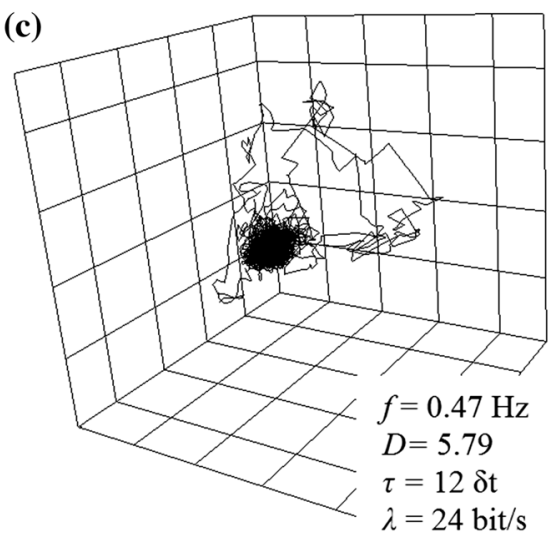

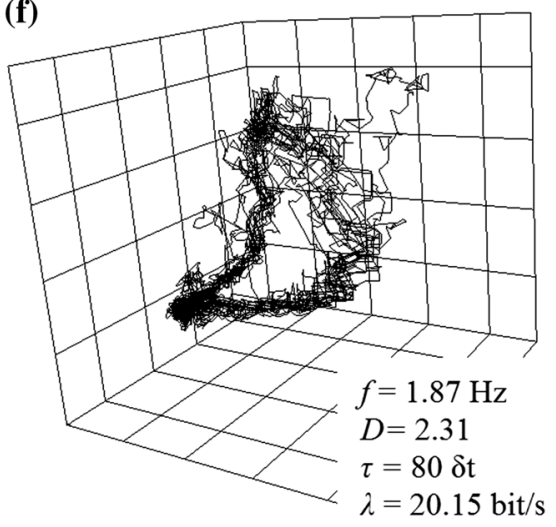

$q=0.0769 \mathrm{l} / \mathrm{min}$. In this case Lyapunov exponent describes fluctuations during the alternative bubble departures. In the case of synthetic oil, changes in the Lyapunov exponent have a similar character, however, for $q=0.0333 \mathrm{l} / \mathrm{min}$, the changes are more chaotic than in a mineral oil. For $q=0.07691 / \mathrm{min}$ the alternative bubble departures are interrupted by simultaneous bubble departures - more often than in case of mineral oil.

It may be concluded that for mineral and synthetic oils, the increase of air volume flow rates causes a decrease in the correlation dimension. It can be assumed that decrease in the correlation dimension is associated with a decrease in the frequency of bubble departures. The decrease in the correlation dimension 
is associated with an increase in the duration of the alternative bubble departures. We can say that the alternative bubble departures organize the flow of bubbles-simplifying its complexity. The process of self-organizing bubble departures appear.

\section{Conclusions}

The self-organizing bubble departures of bubble departures from twin nozzles in engine oils were analysed. In the experiment the alternative and simultaneous bubble departures were observed and their stability was analysed. The analysis of pressure fluctuations during occurrence of self-organizing bubble departures bubble departures showed that in the one of two nozzles the fluctuations took place between two constant pressure values. In this nozzle the mean pressure was slightly greater than in the neighbour nozzle. In alternative bubble departures the mean air pressure in the neighbour nozzle systematically decreases. Finally, it leads to the disappearance of alternative bubble departures, which causes an increase in the pressure in the air supply system of neighbour nozzle. The alternative bubble departure appears again, the mentioned process is repeated in a cyclic way in a mineral oil and in a chaotic way in the synthetic oil.

We can conclude that instability of alternative bubble departures leads to equalization of pressures in the both nozzle air supply systems, which makes that simultaneous bubble departures appear.

In our experiment one of the nozzles (left nozzle) was the "master" nozzle. The frequency of bubble departures from twin nozzles was determined by frequency of bubble departures from this "master" nozzle. The neighbouring nozzle was the "slave" nozzle, in gas supply system of this nozzle the air pressure changed chaotically. The master nozzle is the nozzle from which bubbles departs with higher frequency. In such a way the periodic and chaotic systems were synchronized causing the occurrence of self-organizing bubble departures (periodic bubble departures).

Nonlinear analysis of bubble departure synchronizations showed that:
- In a synthetic oil the alternative bubble departure is interrupted by simultaneous bubble departuresmore frequently than in the case of mineral oil,

- The alternative bubble departures organize the flow of bubbles-simplifying the complexity of bubble departures from twin nozzles,

- The transitions between alternative and simultaneous bubble departures can be quasi periodic or chaotic.

The obtained results show, that the way of bubble departures from two neighbouring nozzles does not depend in a simple way on the character of pressure fluctuations in the nozzle air supply systems. Chaotic changes in the air pressure oscillations do not always determine the chaotic bubble departures. Such situations occur in alternative bubble departures in engine oil.

In paper [12] it was shown that periodic bubble departure, from the single nozzle, can be stabilized by the increase of air volume flow rate. In case when bubbles are generated from two neighbouring nozzles the periodic bubble departures are stabilized by the occurrence of self-organizing bubble departures.

Acknowledgements The study has been accomplished under the research Project UMO-2011/03/N/ST8/04079 financed by the Polish National Science Centre.

\section{Compliance with ethical standards}

Conflict of interest The authors declare that they have no conflict of interest.

Open Access This article is distributed under the terms of the Creative Commons Attribution 4.0 International License (http:// creativecommons.org/licenses/by/4.0/), which permits unrestricted use, distribution, and reproduction in any medium, provided you give appropriate credit to the original author(s) and the source, provide a link to the Creative Commons license, and indicate if changes were made.

\section{References}

1. Xie S, Tan RBH (2003) Bubble formation at multiple orifices-bubbling synchronicity and frequency. Chem Eng Sci 58:4639-4647

2. Mosdorf R, Wyszkowski T (2013) Self-organising structure of bubbles departures. Int J Heat Mass Transf 61:277-286

3. Mosdorf R, Wyszkowski T (2011) Experimental investigations of deterministic chaos appearance in bubbling flow. Int J Heat Mass Transf 54:5060-5069 
4. Femat R, Ramirez JA, Soria A (1998) Chaotic flow structure in a vertical bubble column. Phys Lett A 248(1):67-79

5. Dzienis P, Mosdorf R (2014) Stability of periodic bubble departures at a low frequency. Chem Eng Sci 109:171-182

6. Mosdorf R, Dzienis P, Litak G (2017) The loss of synchronization between air pressure fluctuations and liquid flow inside the nozzle during the chaotic bubble departures. Meccanica 52:2641-2654

7. Kazakis NA, Mouza AA, Paras SV (2008) Coalescence during bubble formation at two neighbouring pores: an experimental study in microscopic scale. Chem Eng Sci 63(21):5160-5178

8. Sanada T, Sato A, Shirota MT, Watanabe M (2009) Motion and coalescence of a pair of bubbles rising side by side. Chem Eng Sci 64:2659-2671

9. Legendre D, Magnaudet J, Mougin G (2003) Hydrodynamic interactions between two spherical bubbles rising side by side in a viscous liquid. J Fluid Mech 497:133-166

10. Snabre P, Magnifotcham F (1997) Formation and rise of a bubble stream in viscous liquid. Eur Phys J B 4:369-377

11. Lei Zhang L, Shoji M (2001) Aperiodic bubble formation from a submerged orifice. Chem Eng Sci 56:5371-5381

12. Cieslinski JT, Mosdorf R (2005) Gas bubble dynamicsexperiment and fractal analysis. Int $\mathrm{J}$ Heat Mass Transf 48:1808-1818
13. Leifer I, Tang D (2007) The acoustic signature of marine seep bubbles. JASA Express Lett. https://doi.org/10.1121/1. 2401227

14. Vazquez A, Manasseh R, Chicharro R (2014) Can acoustic emissions be used to size bubbles seeping from a sediment bed? Chem Eng Sci 131:187-196

15. Lavensona DM, Kelkara AV, Daniel AB, Mohammad SA, Koubab G, Aicheleb CP (2016) Gas evolution rates-a critical uncertainty in challenged gas-liquid separations. J Pet Sci Eng 147:816-828

16. Hedengren KH (1988) Decomposition of edge operators. 9th Int Conf Pattern Recognit 14(2):963-965

17. Schuster HG (1988) Deterministic chaos. An introduction, II edn. Wiley, Hoboken

18. Wolf A, Swift JB, Swinney HL, Vastano JA (1985) Determining Lyapunov exponent from a time series. Phys D 16:285-317

19. Grassberger P, Procaccia I (1983) Measuring the strangeness of strange attractors. Phys D 9:189-208

Publisher's Note Springer Nature remains neutral with regard to jurisdictional claims in published maps and institutional affiliations. 